Short communication

\title{
Synthesis and biological evaluation of fluorinated 1,5-diarylpyrrole-3- alkoxyethyl ether derivatives as selective COX-2 inhibitors endowed with anti-inflammatory activity
}

\author{
Angela Di Capua ${ }^{a, 1}$, Claudia Sticozzi ${ }^{b}$, Simone Brogi a , Margherita Brindisi ${ }^{a}$, \\ Andrea Cappelli a , Lidia Sautebin ${ }^{\text { }}$, Antonietta Rossi ${ }^{\text {c }}$, Simona Pace ${ }^{\text {c }}$, Carla Ghelardini ${ }^{\text {d, }}$ \\ Lorenzo Di Cesare Mannelli ${ }^{\mathrm{d}}$, Giuseppe Valacchi ${ }^{\mathrm{b}, \mathrm{e}}{ }^{\text {, Gianluca Giorgi a , Antonio Giordani }}$, \\ Giovanna Poce ${ }^{\mathrm{g}}$, Mariangela Biava ${ }^{\mathrm{g}}$, Maurizio Anzini ${ }^{\mathrm{a}, *}$ \\ a Department of Biotechnology, Chemistry and Pharmacy, University of Siena, Via Aldo Moro 2, 53100 Siena, Italy \\ b Department of Life Sciences and Biotechnology, University of Ferrara, Via Luigi Borsari 46, 44121 Ferrara, Italy \\ c Department of Pharmacy, University of Naples "Federico II", Via D. Montesano 49, I-80131, Napoli, Italy \\ d Department of Pharmacology Neuroscience, Psychology, Drug Research and Child Health - Neurofarba, Pharmacology and Toxicology Section, University \\ of Florence, Viale G. Pieraccini 6, I-50139 Firenze, Italy \\ Department of Food and Nutrition, Kyung Hee University, Seoul, South Korea \\ ${ }^{\mathrm{f}}$ Rottapharm Biotech, Via Valosa di Sopra 7, 20052 Monza, Italy \\ ${ }^{g}$ Department of Chemical Studies and Technologies of Drugs, University of Rome "La Sapienza”, Piazzale Aldo Moro 5, 00185 Roma, Italy
}

\section{A R T I C L E I N F O}

\section{Article history:}

Received 7 October 2015

Received in revised form 22 December 2015

Accepted 23 December 2015

Available online 28 December 2015

\section{Keywords:}

COX-2 inhibitors

1,5-diarylpyrrole derivatives

Anti-inflammatory agents

Antinociceptive agents

Antiproliferative activity

Molecular modelling

\begin{abstract}
A B S T R A C T
A series of substituted 1,5-diarylpyrrole-3-alkoxyethyl ethers were previously synthesized and the potential anti-inflammatory and antinociceptive activities of these compounds were evaluated in vivo. The compounds displayed a very good activity against both carrageenan-induced hyperalgesia and oedema in the rat paw test. Therefore, in a very preliminary test, compounds $(\mathbf{8 a}, \mathbf{b})$ showed antiproliferative activity in the HaCaT (aneuploid immortal keratinocyte from adult human skin) cell models. On these basis, our research continued with the synthesis of fluorinated derivatives $(\mathbf{8 c}, \mathbf{d}, \mathbf{9 b}-\mathbf{d}$, and $\mathbf{1 0 b}-\mathbf{d})$ with the aim of improving the pharmacokinetic profile of the previous active compounds. Substitution of a hydrogen atom by a fluorine atom may change the conformational preferences of the molecules due to stereoelectronic effects and also fluorine atom may be able to exert the metabolic obstruction reducing the "first-pass effect". Compound 10b exhibited a prominent in vivo anti-inflammatory and antinociceptive activities, in addition its antiproliferative power in an in vitro model of human skin cancer is herein described.
\end{abstract}

๑) 2015 Elsevier Masson SAS. All rights reserved.

\section{Introduction}

Prostaglandin G/H synthase enzymes (PGHS), commonly known as cyclooxygenases (COX), are responsible for the formation of important biological mediators called prostanoids, which play a critical role in various biological processes [1]. Arachidonic acid (AA) is a 20 carbon unsaturated fatty acid distributed throughout the lipid bilayer of the cell membranes. Phospholipase A2 (PLA2)

\footnotetext{
* Corresponding author.

E-mail address: maurizio.anzini@unisi.it (M. Anzini).

1 Present address: Eskitis Institute for Drug Discovery, Griffith University, Brisbane, Queensland, Australia.
}

enzymes cleave membrane bound arachidonate for the conversion into bioactive precursors. AA can be metabolized through COX pathway via a two-step process: the first step involves conversion of AA to prostaglandin $\mathrm{G} 2$ ( $\left.\mathrm{PGG}_{2}\right)$, a 9,11-endoperoxide-15hydroperoxide, and in the second step peroxidase reduces $\mathrm{PGG}_{2}$ to prostaglandin $\mathrm{H}_{2}\left(\mathrm{PGH}_{2}\right)$. Specific PG synthases further metabolize $\mathrm{PGH}_{2}$ to give structurally related bioactive lipids, including PGs $\mathrm{PGE}_{2}, \mathrm{PGD}_{2}, \mathrm{PGF}_{2 \alpha}$, prostacycline $\mathrm{PGI}_{2}$ and thromboxane $\mathrm{A}_{2}$ (TxA2) [2].

Non-Steroidal Anti-Inflammatory Drugs (NSAID), which include both traditional NSAIDs ( $t$ NSAIDs) and selective inhibitors of COX-2 (COXib) (Fig. 1), relieve pain and inflammation suppressing the COX function of PGHS and the consequent formation of $\mathrm{PGE}_{2}$ and 


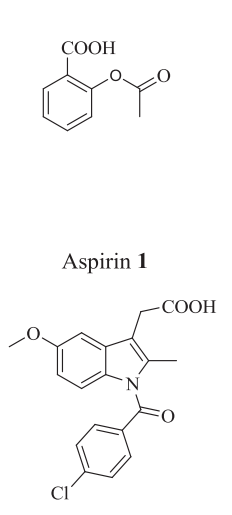

Indomethacin 4

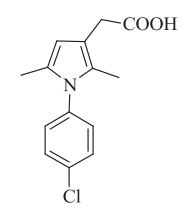

Clopirac 2

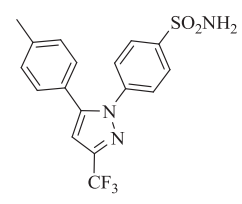

Celecoxib 5

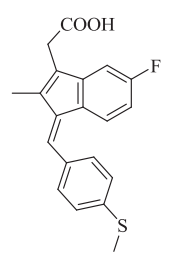

Sulindac 3

$\mathrm{H}_{3} \mathrm{CO}_{2} \mathrm{~S}$

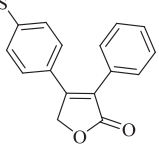

Rofecoxib 6
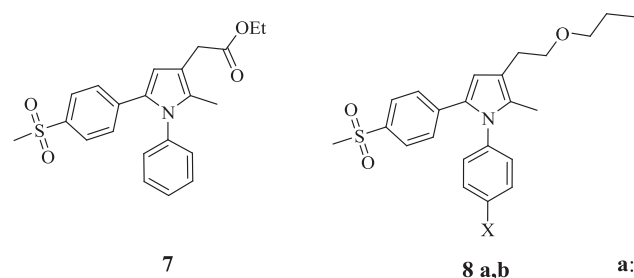

8 a,b

a: $X=H$
b: $X=F$

Fig. 1. Structures of reference compounds.

prostacyclin $\left(\mathrm{PGI}_{2}\right)$, along with other prostanoids [1].

Long-term therapy with tNSAIDs generates adverse gastrointestinal complications ranging from stomach erosions and silent intestinal ulcerations to life-threatening complications [3]. Selective inhibitors of COX-2 depress prostacyclin ( $\left.\mathrm{PGI}_{2}\right)$, an atheroprotective agent, but not COX-1-derived thromboxane $\mathrm{A}_{2}\left(\mathrm{TXA}_{2}\right)$, a proaggregatory and vasoconstrictor mediator, which might predispose patients to heart attack and stroke [4]. In 2004, Rofecoxib, (4-[4(methylsulfonyl)phenyl]-3-phenyl-2(5H)-furanone), marketed as Vioxx was withdrawn from the market due to increased risk for cardiovascular thrombotic events in a long term-therapy [5].

Moreover, the involvement of COX-2 in cancer development was previously evidenced by pharmacological analysis of PGs in different human cancers. PGE 2 specifically exerts carcinogenic effects in the human body. It was found that premalignant lesions and established cancers produce excessive quantities of $\mathrm{PGE}_{2}$ and this enhances tumor cell growth and increases tumor invasiveness [1]. COX-2 is up-regulated in a number of epithelial cancers, including those originating in the colon and rectum, stomach, breast, prostate, and lung [6]. In the context of cutaneous tissues, increased expression of COX-2 and production of its primary product $\mathrm{PGE}_{2}$ have been reported to increase cell growth and decrease apoptosis. $\mathrm{PGE}_{2}$ is also thought to be responsible for different skin cancers, such as squamous cell and basal cell carcinoma [7].

During the last decade a large number of COX inhibitors have been described. In particular, very recently novel chemical entities have been identified by different approaches such as: i) rational design providing novel scaffolds based on 4-phenylpyrimidine2(1H)-thiones [8] and, indole based peptidomimetics [9], or ii) computational procedures providing novel and structurally unrelated COX-2 inhibitors [10].

Within a large programme devoted to the design and synthesis of new anti-inflammatory agents based on a diaryl heterocyclic scaffold, we previously synthesized different series of 1,5diarylpyrrole-3-acetic esters 7 [11] and 3-alkoxyethyl ethers 8a,b [12] as new selective COX-2 inhibitors, in which the pyrroloacetic subunit, reminiscent of indomethacine and clopirac was conjugated with vicinal diaryl moiety mimicking the main feature of COXib (Fig. 1).

These compounds were shown to be potent and highly selective COX-2 inhibitors in in vitro cell culture assays [12-14]. The potential anti-inflammatory and antinociceptive activities of these compounds were also evaluated in vivo, demonstrating a very good activity against both carrageenan induced hyperalgesia and oedema in rat paw test. Furthermore, compounds 8a,b showed, in a very preliminary screening, a clear inhibition of cell proliferation on HaCaT cells with non-toxic effects in the range between 10 and $100 \mu \mathrm{M}[7]$.

Encouraged by these data, we focused our attention on the preparation of two homologous series of differently fluorinated 3substituted-1,5-diarylpyrrole alkoxyethyl ethers (8c,d; 9b-d and 10b-d) (Fig. 2) with the aim of investigating the biological effects that can be elicited by the insertion of a fluorine atom on different portion of the previously synthesized COX-2 inhibitors. Compound 10b, which displays the best biological profile in terms of affinity and selectivity toward COX-2, as well as percent inhibition of the enzyme (cell culture assay), was also investigated for its in vivo anti-inflammatory, analgesic and antiproliferative activity, displaying interesting results.

\section{Results and discussion}

\subsection{Chemistry}

The synthetic procedure used to obtain final compounds $\mathbf{8 c}, \mathbf{d}$, 9b-d and 10b-d is depicted in Scheme 1. Briefly, the suitable alcohols 11c-d were treated with propyl iodide in $\mathrm{NaOH} 50 \%(\mathrm{w} / \mathrm{w})$ solution, following the previously reported procedure [12] to obtain final compounds $\mathbf{8 c}$,d. Using the same procedure, derivatives 11b-d were treated with the proper hydroxyalkyl bromide in its tetrahydropyranyl protected form [15] (see Supplementary Material) to yield compounds $\mathbf{1 2 b}$-d and $\mathbf{1 3 b}$-d that were successively deprotected to give hydroxyalkyl ethers $\mathbf{1 4 b}$-d and $\mathbf{1 5 b}$-d. These derivatives were then activated by tosylation and treated with $\mathrm{Bu}_{4} \mathrm{~N}^{+} \mathrm{F}^{-}$to afford fluorinated compounds $\mathbf{9 b - d}$ and 10b-d in satisfactory yield. Purity of compounds $\mathbf{8 c , d}, \mathbf{9 b}-\mathbf{d}, \mathbf{1 0 b}-\mathbf{d}$ was assessed by RP-HPLC and was found to be higher than 95\% (see Supplementary Material for further details).

\subsection{Structure-activity relationship, molecular modeling studies and biological evaluation}

In this limited series of compounds the presence of an additional fluorine atom in the 3-alkoxyalkyl side-chain with respect to compounds $\mathbf{8 a , b}$ would allow us to assess if the contemporary presence of fluorine atoms in two different portions of the molecule could influence the interaction of these new inhibitors with the COX-2 active site. In particular, compounds $\mathbf{8 c , d}$ were synthesized
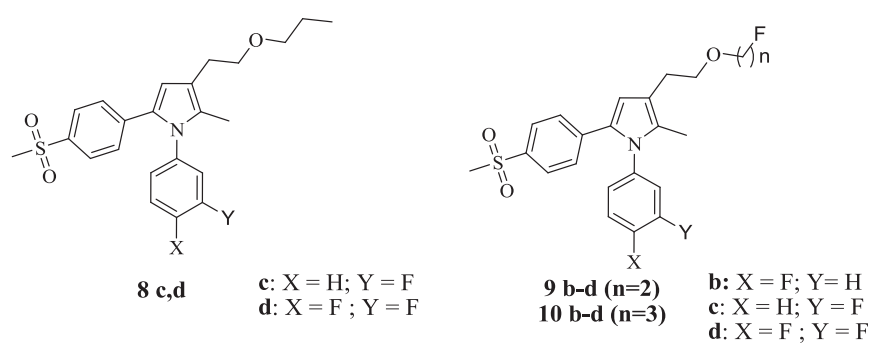

Fig. 2. Structure of fluorinated compounds $\mathbf{8 c , d}, \mathbf{9 b}-\mathbf{d}$ and $\mathbf{1 0 b}-\mathbf{d}$. 

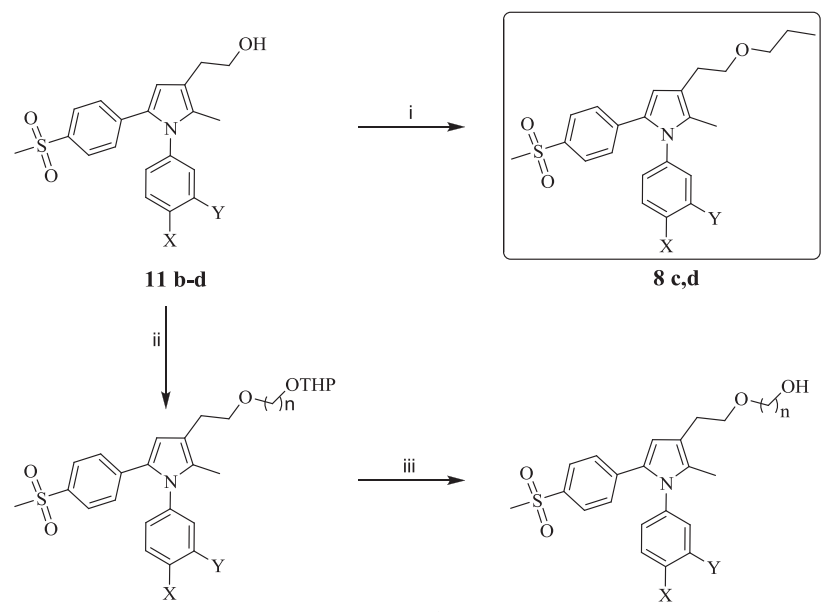

$12 \mathrm{~b}-\mathrm{d}(\mathrm{n}=2)$ 13 b-d $(n=3)$

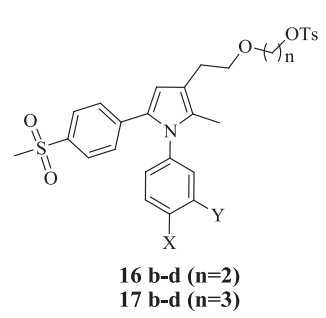

$16 b-d(n=2)$
$17 b-d(n=3)$
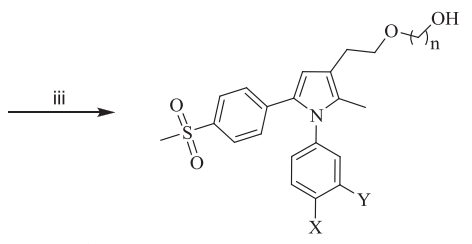

$14 \mathrm{~b}-\mathrm{d}(\mathrm{n}=2)$

$15 \mathrm{~b}-\mathrm{d}(\mathrm{n}=3)$

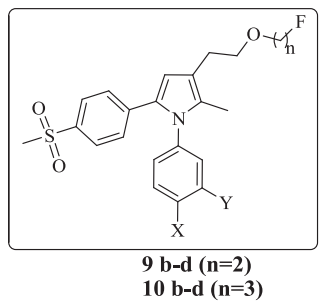

b: $\mathrm{X}=\mathrm{F} ; \mathrm{Y}=\mathrm{H}$

c: $\mathrm{X}=\mathrm{H} ; \mathrm{Y}=\mathrm{F}$

d: $\mathrm{X}=\mathrm{F} ; \mathrm{Y}=\mathrm{F}$
Scheme 1. Synthesis of compounds 8c,d, $\mathbf{9 b}$-d, and 10b-d. Reagents and conditions:(i) Propyl iodide, $\left(\mathrm{Bu}_{4} \mathrm{~N}^{+}\right) \mathrm{Br}^{-}$, Sodium hydroxide, $50 \%(\mathrm{w} / \mathrm{w})$ aqueous solution, $60{ }^{\circ} \mathrm{C}, 72 \mathrm{~h}$; (ii) $\mathrm{Br}\left(\mathrm{CH}_{2}\right)_{n} \mathrm{OTHP},\left(\mathrm{Bu}_{4} \mathrm{~N}^{+}\right) \mathrm{Br}^{-}$, Sodium hydroxide, $50 \%(\mathrm{w} / \mathrm{w})$ aqueous solution, $60{ }^{\circ} \mathrm{C}$, $72 \mathrm{~h}$ (iii) PPTS, $\mathrm{MeOH}, 55{ }^{\circ} \mathrm{C}, 20 \mathrm{~h}$; (iv) DMAP, DIPEA, TsCl, DCM, r.t., 4 h; (v) $\left(\mathrm{Bu}_{4} \mathrm{~N}^{+}\right)$ $\mathrm{F}^{-}$in THF, $1 \mathrm{M}$; dry THF, $80^{\circ} \mathrm{C}, 3 \mathrm{~h}$.

in order to evaluate if the number and the different position of fluoro substituent in the pendant N1 aromatic ring could lead to biological results comparable with those previously reported for compounds 8a and 8b [12].

The effects of a fluorine atom as a substituent on physical and chemical properties, as lipophilicity, electronic properties, hydrogen bonding, and metabolic stability are well known [16,17]. The difference in electronegativity between carbon and fluorine generates a large dipole moment in this bond that, when combined with the electrostatic distribution of a specific molecule, may contribute to the molecule's ability to establish intermolecular interactions.

By means of in vitro cell culture (J774 murine macrophage) assay, the title compounds were evaluated for their inhibitory potency and selectivity on both COX-isoforms and the results are resumed in Table 1.

Results showed that in compounds $\mathbf{8 c , d}, \mathbf{d}$, the presence of a fluoro substituent in meta and in meta/para position of the pendant N1 ring did not alter the inhibitory potency and selectivity with respect to previously reported analogues 8a,b. In compounds sharing general structures $\mathbf{9}$ and $\mathbf{1 0}$, the replacement of a hydrogen atom with fluorine in the side chain coupled with the presence of monoor difluoro-substitution on the N1 pendant ring led to contrasting effects on the inhibitory activity of the resulting compounds. Accordingly, for meta-substituted compounds $9 \mathrm{c}$ and $10 \mathrm{c}$, a considerable decrease of COX-2 inhibition was observed whereas the para-fluoro derivative $\mathbf{1 0 b}$, showed a significantly improved inhibitory activity $\left(\mathrm{IC}_{50}=0.007 \mu \mathrm{M}\right)$ when compared with that of 1,5-diarylpyrrole-3-propoxyethyl-, 3-fluoroethoxyethyl-, and 3fluoropropoxyethyl ethers $\mathbf{8 a - d ,} \mathbf{9 c}, \mathbf{d}$, and $\mathbf{1 0 c}, \mathbf{d}$, respectively, the $\mathrm{IC}_{50}$ of which ranges from 0.018 to $0.030 \mu \mathrm{M}$. The in vitro potency and selectivity showed by compound 10b appears more striking when compared to that of celecoxib (5) the $\mathrm{IC}_{50}$ of which being $0.079 \mu \mathrm{M}$ (11-fold less potent and much more less selective than 10b).

Next, the new fluorinated derivatives were analysed by means of molecular docking calculations using Glide software (Glide version 5.7, Schrödinger, LLC, New York, NY, 2011), with the aim of investigating the potential binding modes of such inhibitors within the COX-2 binding site. The selected compounds $\mathbf{9 b}$ and $\mathbf{1 0 b}$ differing for one carbon atom in the fluorinated tail, showed a similar binding mode to those found for a previously reported COX2 inhibitors [18]. In particular, compound $\mathbf{9 b}$ strongly interacts with the COX-2 active site by a series of polar contacts with the backbone of Phe518 and with the side-chain of Arg120. Moreover, one $\pi-\pi$ stacking was established between Tyr355 and $\mathbf{9 b}$ (Fig. 3). The fluorophenyl moiety interacts with a series of hydrophobic residues as depicted in Fig. 3B. These interactions of $\mathbf{9 b}$ into COX-2 binding site result in docking XPscore of $-8.47 \mathrm{kcal} / \mathrm{mol}$ and in estimated free binding energy $\left(\Delta \mathrm{G}_{\text {bind }}\right)$ of $-97.74 \mathrm{kcal} / \mathrm{mol}$.

As depicted in Fig. 4, compound 10b showed a similar binding mode with respect to that found for $\mathbf{9 b}$. In fact, $\mathbf{1 0 b}$ established the same hydrophobic/polar contacts previously described. Also, the docking score and the estimated free binding energy resulted comparable to those calculated for $9 \mathbf{b}$ (XPscore $-9.27 \mathrm{kcal} / \mathrm{mol}$; $\Delta \mathrm{G}_{\text {bind }}-100.97 \mathrm{kcal} / \mathrm{mol}$ ). Remarkably, all the newly synthesized compounds reported in Table 1 showed a comparable binding mode as well as the docking score and the estimated $\Delta \mathrm{G}_{\text {bind }}$ (data not shown), confirming the strong affinity of this kind of scaffold for COX-2 enzyme.

On the basis of its very encouraging in vitro COX-2 inhibitory activity, compound 10b was evaluated in a rat model of acute inflammatory pain. As shown in Table 2, inflammatory pain was induced by the intraplantar administration of carrageenan.

The anti-inflammatory effect of the new compounds emerged also by the measurement of the paw edema volume, it was significantly decreased by $\mathbf{1 0 b}\left(3-20 \mathrm{mg} \mathrm{kg}^{-1}\right.$ ) (Table 2 ). To evaluate the pain reliever profile of the active compound $\mathbf{1 0 b}$, its antinociceptive efficacy and potency was assessed in the model of visceral pain induced by the intraperitoneal (i.p.) injection of a $0.6 \%$ acetic acid solution (Writhing test). The abdominal contractions induced by the acid solution (about 30 writhing in vehicle-treated animals, Table 3), were dose-dependently prevented by the administration p.o. of 10b. The measurement performed 30 min after $20 \mathrm{mg} \mathrm{kg}^{-1}$ 10b treatment showed a number of writhing reduced to $10.7 \pm 2.5$ (Table 3).

The efficacy of compound 10b was also evaluated in the rat osteoarthritis model induced by the intra-articular injection of monoiodoacetate (MIA) (Table 4). The injection of MIA in the knee joint induces necrosis of chondrocytes with decrease of cartilage thickness and osteolysis [19]. Kobayashi et al. showed that MIA is able to disorganize chondrocytes and to promote cartilage erosion [20]. These alterations are comparable with joint damages typical of humans affected by osteoarthritis [21-23]. Briefly, on day 14 after MIA injection the pain threshold on the ipsilateral paw was decreased to $39.2 \pm 3.2 \mathrm{~g}$ in comparison to $62.9 \pm 2.3 \mathrm{~g}$ of control rats as evaluated by Paw pressure test. Compound administered p.o. was able to reduce articular pain starting from the dosage of $3 \mathrm{mg} \mathrm{kg}^{-1}$. Twenty $\mathrm{mg} \mathrm{kg}^{-1}$ of $\mathbf{1 0 b}$ were effective up to $60 \mathrm{~min}$ after treatment reaching the threshold of $54.5 \pm 3.5 \mathrm{~g}(60 \mathrm{~min}$, Table 4$)$. The repeated treatment with $\mathbf{1 0 b}$ significantly prevented MIA dependent hyperalgesia (before treatment). A further compound administration (after treatment, $30 \mathrm{~min}$ ) did not induce an additive 
Table 1

In vitro inhibition (J774 murine macrophage assay) of COX-1 and COX-2 by compounds 8a-d, 9b-d, and $\mathbf{1 0 b}-\mathbf{d}$.

\begin{tabular}{|c|c|c|c|c|c|c|}
\hline Cpd & $\mathrm{X}$ & $\mathrm{Y}$ & $\mathrm{n}$ & COX-1 IC $50(\mu \mathrm{M})^{\mathrm{a}}$ & COX-2 IC ${ }_{50}(\mu \mathrm{M})^{\mathrm{a}}$ & $\mathrm{COX}-1 / \mathrm{COX}-2(\mathrm{SI})^{\mathrm{b}}$ \\
\hline $8 a^{c}$ & $\mathrm{H}$ & $\mathrm{F}$ & - & $>100$ & 0.018 & $>5555$ \\
\hline $\mathbf{8 b}^{c}$ & $\mathrm{~F}$ & $\mathrm{~F}$ & - & $>100$ & 0.030 & $>3333$ \\
\hline $8 c$ & $\mathrm{H}$ & $\mathrm{F}$ & - & $>100$ & 0.013 & $>7692$ \\
\hline $8 d$ & $\mathrm{~F}$ & $\mathrm{~F}$ & - & $>100$ & 0.018 & $>5555$ \\
\hline $9 b$ & $\mathrm{~F}$ & $\mathrm{H}$ & 2 & $>100$ & 0.013 & $>7692$ \\
\hline $9 c$ & $\mathrm{H}$ & $\mathrm{F}$ & 2 & $>100$ & 0.140 & $>714$ \\
\hline 9d & $\mathrm{F}$ & $\mathrm{F}$ & 2 & $>100$ & 0.029 & $>3448$ \\
\hline $10 b$ & $\mathrm{~F}$ & $\mathrm{H}$ & 3 & $>100$ & 0.007 & $>14,285$ \\
\hline $10 \mathrm{c}$ & $\mathrm{H}$ & $\mathrm{F}$ & 3 & $>100$ & 0.135 & $>2857$ \\
\hline 10d & $\mathrm{F}$ & $\mathrm{F}$ & 3 & $>100$ & 0.019 & $>5263$ \\
\hline Celecoxib $^{\mathrm{d}}$ & & & & 5.1 & 0.079 & 65 \\
\hline
\end{tabular}

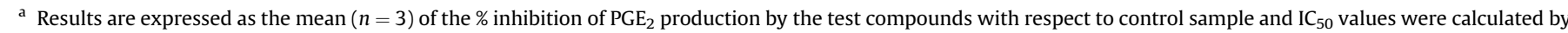
GraphPad Instat program.

b $\mathrm{IC}_{50}(\mathrm{COX}-1) / \mathrm{IC}_{50}(\mathrm{COX}-2)$

c See Ref. [12].

d See Ref. [13].

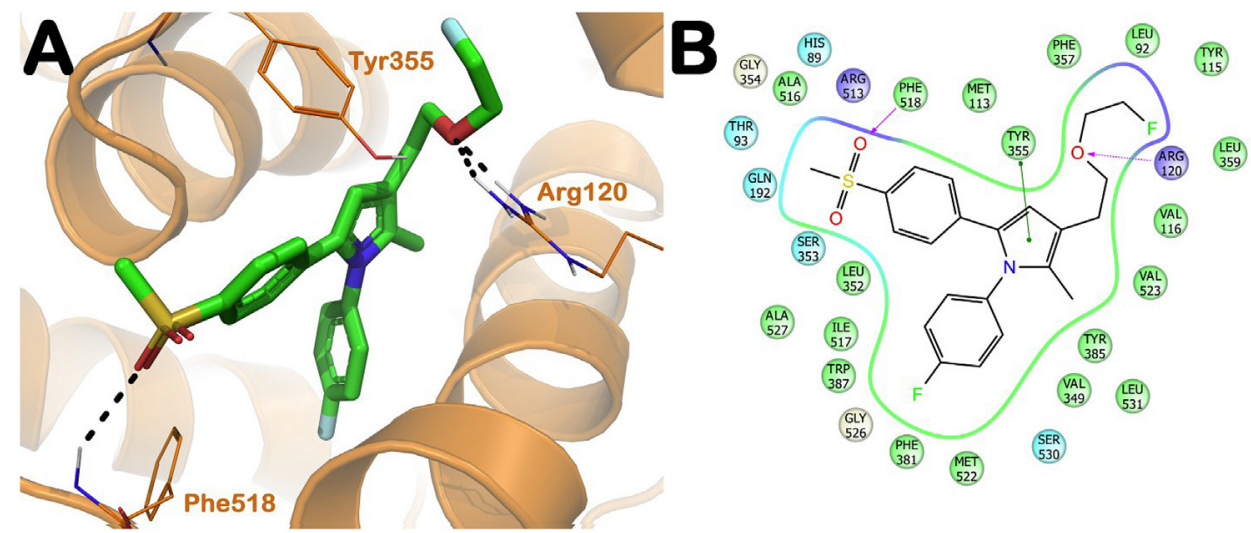

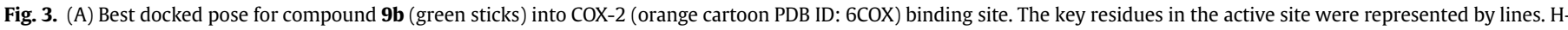

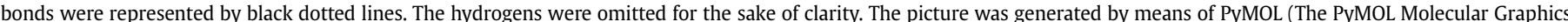

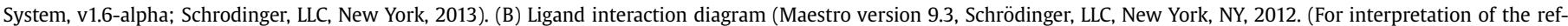
erences to colour in this figure legend, the reader is referred to the web version of this article.)
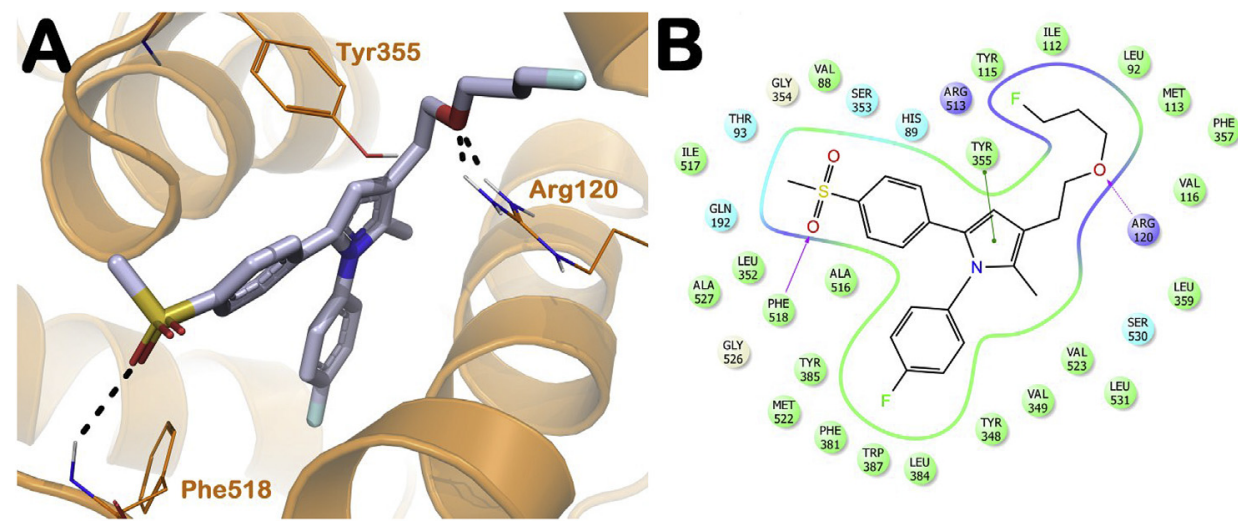

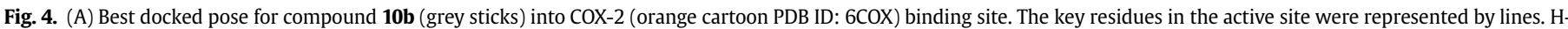

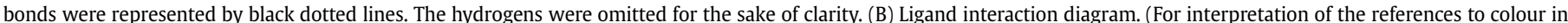
this figure legend, the reader is referred to the web version of this article.)

acute antihyperalgesic effect, suggesting that a repeated treatment with the present anti-inflammatory compounds could be able to prevent the joint damage and, consequently, pain [21-24].

In addition to the canonical anti-inflammatory and antinociceptive activities, many studies highlighted the potential of COX-2 inhibitors in the prevention of several cancer types such as colon, breast, lung and prostate cancers [25-28] most likely by modulating the cell proliferation pathways. So, title compounds were evaluated to assess their effects on cell toxicity by means of LDH release assay and potential antiproliferative activity using $\mathrm{HaCaT}$, aneuploid immortal keratinocyte cell line from adult human skin [7]. 
Table 2

Effect of 10b on carrageenan-induced acute inflammatory pain hypersensitivity (paw-pressure test) and paw edema.

\begin{tabular}{|c|c|c|c|c|c|c|c|c|}
\hline \multicolumn{4}{|l|}{ Paw-pressure (g) } & \multicolumn{5}{|c|}{ Paw volume (mL) } \\
\hline \multirow[t]{2}{*}{ Pre-treatment intraplantar } & \multirow[t]{2}{*}{ Treatment per os } & \multirow[t]{2}{*}{ Dose $\mathrm{mg} \mathrm{kg}^{-1}$} & \multirow[t]{2}{*}{ Before treatment } & \multicolumn{5}{|c|}{ After treatment } \\
\hline & & & & $30 \mathrm{~min}$ & $60 \mathrm{~min}$ & $90 \mathrm{~min}$ & $120 \mathrm{~min}$ & $60 \mathrm{~min}$ \\
\hline Vehicle & Vehicle & & $57.6 \pm 2.2$ & $63.8 \pm 2.9$ & $59.4 \pm 3.3$ & $62.7 \pm 2.8$ & $64.6 \pm 3.2$ & $1.45 \pm 0.08$ \\
\hline Carrageenan & Vehicle & & $33.9 \pm 3.1$ & $34.1 \pm 2.3$ & $35.4 \pm 3.6$ & $37.2 \pm 3.4$ & $34.5 \pm 4.4$ & $2.73 \pm 0.07$ \\
\hline Carrageenan & $10 b$ & 3 & $30.5 \pm 2.6$ & $45.2 \pm 4.6^{* *}$ & $49.2 \pm 3.7^{* *}$ & $44.8 \pm 3.0$ & $36.2 \pm 3.3$ & $2.38 \pm 0.06^{*}$ \\
\hline Carrageenan & 10b & 10 & $31.8 \pm 2.7$ & $51.7 \pm 4.1^{* *}$ & $53.5 \pm 3.9^{* *}$ & $47.2 \pm 4.4^{* *}$ & $38.1 \pm 2.9$ & $2.15 \pm 0.08^{* *}$ \\
\hline Carrageenan & $10 b$ & 20 & $30.5 \pm 2.0$ & $53.9 \pm 3.7^{* *}$ & $56.3 \pm 4.6^{* *}$ & $44.9 \pm 3.7^{* *}$ & $35.5 \pm 2.6$ & $2.06 \pm 0.05^{* *}$ \\
\hline
\end{tabular}

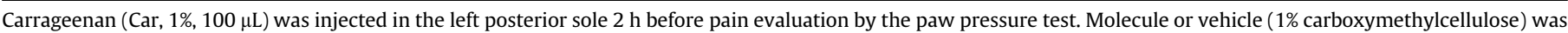

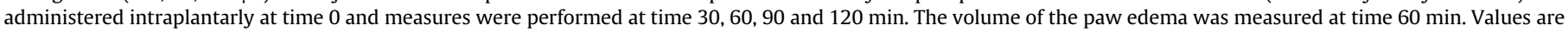
the mean \pm s.e.m. of 6 animals. ${ }^{*} \mathrm{P}<0.05$ and ${ }^{* *} \mathrm{P}<0.01 v s$ the carrageenan + vehicle group.

Table 3

Effect of 10b in the mouse abdominal contraction test (acetic acid 0.6\%)

\begin{tabular}{|c|c|c|c|}
\hline Treatment per os & Dose $\mathrm{mg} \mathrm{kg}^{-1}$ & Number of writhes $30 \mathrm{~min}$ & Number of writhes $60 \mathrm{~min}$ \\
\hline Vehicle & & $30.5 \pm 1.7$ & $32.5 \pm 2.4$ \\
\hline \multirow[t]{3}{*}{ 10b } & 3 & $21.8 \pm 2.5^{* *}$ & $24.6 \pm 2.7^{*}$ \\
\hline & 10 & $11.4 \pm 3.1^{* *}$ & $17.7 \pm 3.1^{* *}$ \\
\hline & 20 & $10.7 \pm 2.5^{* *}$ & $16.9 \pm 2.7^{* *}$ \\
\hline
\end{tabular}

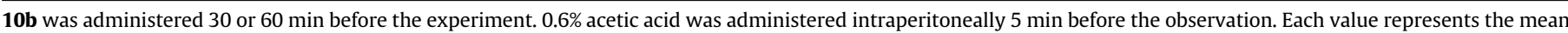
of 12 mice per group. ${ }^{*} \mathrm{P}<0.05$ and ${ }^{* *} \mathrm{P}<0.01$ versus vehicle-treated mice.

Table 4

Effect of 10b on monoiodoacetate-induced osteoarthritis hypersensitivity in the rat paw-pressure test.

\begin{tabular}{|c|c|c|c|c|c|c|c|}
\hline \multirow[t]{3}{*}{ Pre-treatment intraplantar } & \multirow[t]{3}{*}{ Treatment per os } & \multirow[t]{3}{*}{ Dose $\mathrm{mg} \mathrm{kg}^{-1}$} & \multirow[t]{3}{*}{ Before treatment } & \multicolumn{4}{|c|}{ Paw-pressure (g) } \\
\hline & & & & \multicolumn{4}{|c|}{ After treatment } \\
\hline & & & & $30 \mathrm{~min}$ & $60 \mathrm{~min}$ & $90 \mathrm{~min}$ & $120 \mathrm{~min}$ \\
\hline Vehicle & Vehicle & & $62.9 \pm 2.3$ & $60.5 \pm 2.4$ & $58.3 \pm 4.0$ & $66.3 \pm 4.1$ & $61.5 \pm 3.2$ \\
\hline MIA & Vehicle & & $39.2 \pm 3.2$ & $37.8 \pm 3.3$ & $36.1 \pm 3.5$ & $37.8 \pm 3.1$ & $39.2 \pm 4.0$ \\
\hline \multirow[t]{3}{*}{ MIA } & $10 b$ & 3 & $36.5 \pm 2.5$ & $47.9 \pm 4.2^{* *}$ & $45.4 \pm 3.8^{*}$ & $42.4 \pm 3.5$ & $39.0 \pm 3.1$ \\
\hline & & 10 & $38.8 \pm 2.8$ & $50.3 \pm 4.4^{* *}$ & $51.8 \pm 3.7^{* *}$ & $44.3 \pm 3.8$ & $40.6 \pm 3.5$ \\
\hline & & 20 & $37.8 \pm 2.2$ & $51.3 \pm 3.3^{* *}$ & $54.5 \pm 3.5^{* *}$ & $43.8 \pm 3.1$ & $37.1 \pm 2.9$ \\
\hline
\end{tabular}

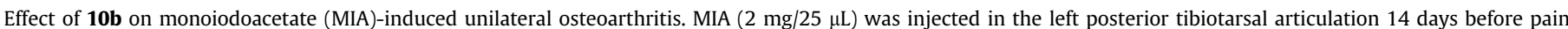

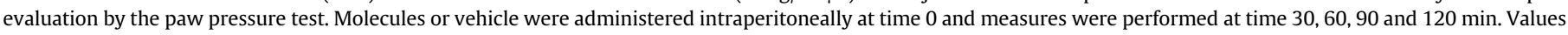
are the mean \pm s.e.m. of 6 rats. ${ }^{*} \mathrm{P}<0.05$ and ${ }^{* *} \mathrm{P}<0.01$ in comparison with MIA + vehicle treated rats.

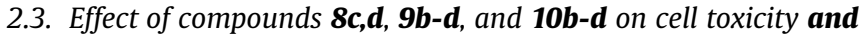 proliferation}

Cytotoxicity of compounds was evaluated in HaCaT cells after treatment with doses ranging from 1 to $50 \mu \mathrm{M}$ by means of LDH release. As shown in Fig. 5, $24 \mathrm{~h}$ after treatment no cytotoxicity was detected.
As shown in Fig. 6, the treatment with compounds $\mathbf{8 c , d}, \mathbf{9 b - d}$, and 10b-d for $24 \mathrm{~h}$, had a clear dose-dependent effect on cellular proliferation as measured by 5-bromo-2'-deoxyuridine (BrdU) incorporation. Indeed, while $1 \mu \mathrm{M}$ did modify cellular proliferation, the treatment with higher albeit not toxic doses (10 and $50 \mu \mathrm{M})$ evidenced a drastic and significant cellular growth inhibition for 8d, 9b, 9c 9d, 10b and 10d compared to the control cells (DMSO

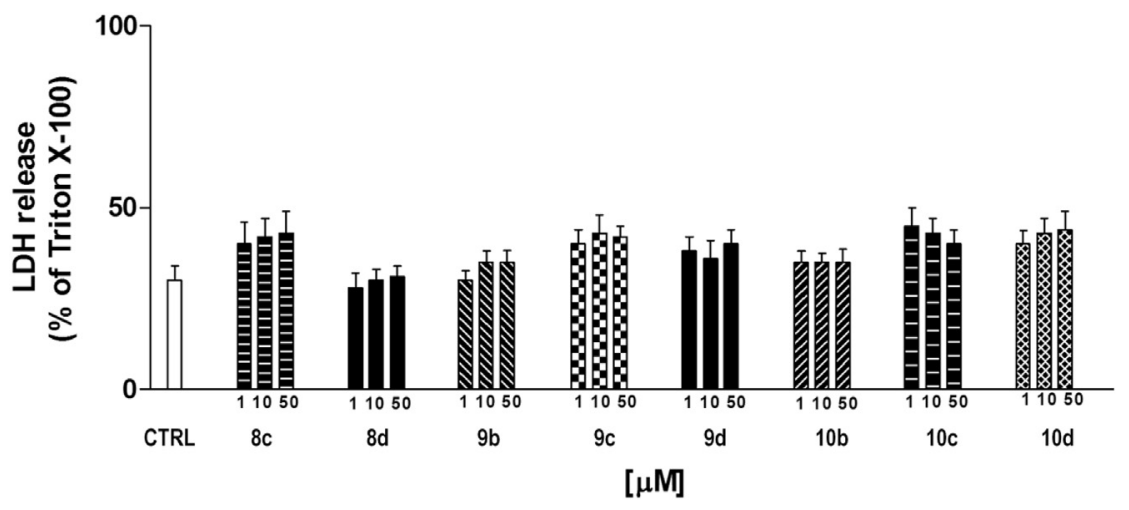

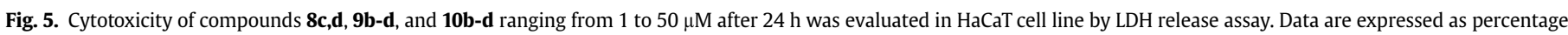
of Triton X-100 (100\%) (averages of three different experiments, ${ }^{*} \mathrm{p}<0.05$ ). 


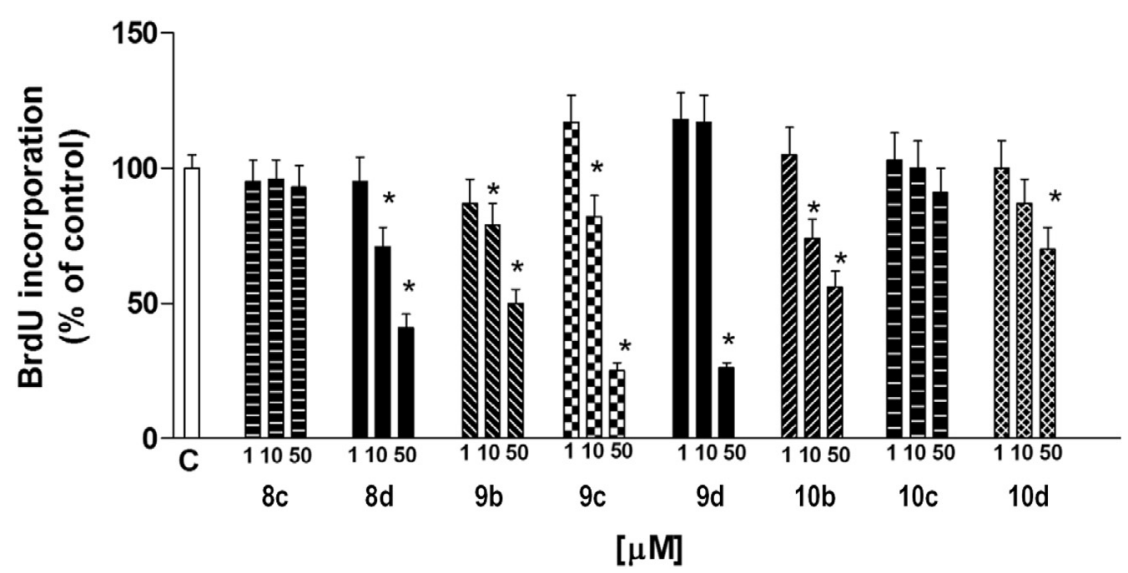

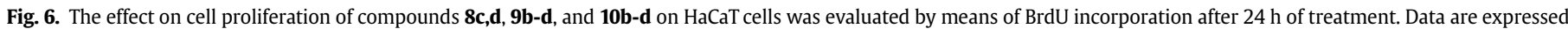
as percentage of control (averages of three different experiments, ${ }^{*} \mathrm{p}<0.05$ ).

0.1\%). Cells treated with $\mathbf{8 c}$ and $\mathbf{1 0 c}$ did not show any significant changes in BrdU incorporation. However, further investigation is required to confirm the antiproliferative activity showed by previously reported compounds $\mathbf{8 a , b}$ [7].

\section{Conclusions}

In this work, we have designed, synthesized and tested a new series of fluorinated 1,5-diarylpyrrole-3-alkoxyethyl ether derivatives as $\mathrm{COX}-2$ selective inhibitors. In vitro biological results are in full agreement with all the previously published data, demonstrating the high affinity of the 1,5-diarylpyrrole scaffold for COX-2 active site. The affinity was also confirmed by molecular docking calculations, proving that replacement of a hydrogen atom by fluorine in the alkyl side chain didn't modify steric and electronic properties of the newly conceived chemical entities. Compound 10b demonstrated efficacy in the model of rat acute inflammatory pain and in the rat osteoarthritis model; thus, highlighting its favourable potential to turn into a novel anti-inflammatory and antinociceptive agents. Furthermore, the anti-proliferative but not toxic effect of the most promising compounds in the presented series on HaCaT cell suggests a possible application in the therapy of human skin disorders.

\section{Methods}

\subsection{Biological evaluation}

\subsubsection{In vitro inhibition of COX-1 and COX-2 enzymes}

The in vitro COX-1 and COX-2 inhibition of compounds 8a-d, 9bd, and 10b-d was evaluated through cell-based assay employing murine monocyte/macrophage J774 cell lines. The cell line was grown in DMEM supplemented with $2 \mathrm{mM}$ glutamine, $25 \mathrm{mM}$ HEPES, 100 units/mL penicillin, $100 \mu \mathrm{g} / \mathrm{mL}$ streptomycin, $10 \%$ fetal bovine serum (FBS), and $1.2 \%$ sodium pyruvate. Cells were plated in 24 -well culture plates at a density of $2.5 \times 10^{5}$ cells $/ \mathrm{mL}$ and allowed to adhere at $37{ }^{\circ} \mathrm{C}$ in $5 \% \mathrm{CO}_{2}$ for $2 \mathrm{~h}$. Immediately before the experiments, culture medium was replaced with fresh medium and cells were stimulated as described previously [12]. The evaluation of COX-1 inhibitory activity was achieved pre-treating cells with test compounds $(100 \mu \mathrm{M})$ for $15 \mathrm{~min}$ and then incubating them at $37{ }^{\circ} \mathrm{C}$ for $30 \mathrm{~min}$ with $15 \mu \mathrm{M}$ arachidonic acid to activate the constitutive COX. At the end of the incubation, the supernatants were collected for the measurement of $\mathrm{PGE}_{2}$ levels by a radioimmunoassay (RIA). To evaluate COX-2 activity, cells were stimulated for $24 \mathrm{~h}$ with Escherichia coli lipopolysaccharide (LPS, $10 \mu \mathrm{g} / \mathrm{mL}$ ) to induce COX-2, in the absence or presence of test compounds (0.001-10 $\mu \mathrm{M})$. The supernatants were collected for the measurement of PGE2 by means of RIA. Celecoxib was utilized as a reference compound for the selectivity index. Triplicate wells were used for the various conditions of the treatment in the cell culture assay throughout the experiments. Results are expressed as the mean of three experiments, of the \% inhibition of $\mathrm{PGE}_{2}$ production by test compounds with respect to control samples. Data fit was obtained using the sigmoidal dose-response equation (variable slope) (GraphPad software). The $\mathrm{IC}_{50}$ values were calculated by the GraphPad Instat program (GraphPad software).

\subsubsection{Animals}

For all the experiments described below, male CD1 albino mice (23-25 g) or male Sprague-Dawley rats (Harlan, Varese, Italy) weighing approximately $200-250 \mathrm{~g}$ at the beginning of the experimental procedure, were used. Animals were housed in CeSAL (Centro Stabulazione Animali da Laboratorio, University of Florence) and used at least one week after their arrival. Four rats were housed per cage (size $26 \times 41 \mathrm{~cm}$ ); animals were fed a standard laboratory diet and tap water ad libitum, and kept at $23 \pm 1^{\circ} \mathrm{C}$ with a $12 \mathrm{~h}$ light/dark cycle, light at 7 a.m. All animal manipulations were carried out according to the European Community guidelines for animal care (DL 116/92, application of the European Communities Council Directive of 24 November 1986 (86/609/EEC). The ethical policy of the University of Florence complies with the Guide for the Care and Use of Laboratory Animals of the US National Institutes of Health (NIH Publication No. 85-23, revised 1996; University of Florence assurance number: A5278-01). Formal approval to conduct the experiments described was obtained from the Italian Ministry of Health ( $\left.N^{\circ} 54 / 2014-B\right)$ and from the Animal Subjects Review Board of the University of Florence. Experiments involving animals have been reported according to ARRIVE guideline. All efforts were made to minimize animal suffering and to reduce the number of animals used.

\subsubsection{Carrageenan-induced acute inflammatory pain}

One hundred $\mu \mathrm{L}$ of carrageenan solution (Sigma-Aldrich; $1 \%$ in saline) was injected intraplantarly into the rat left hind paw. Two h after carrageen injection, compounds were per os (p.o.) administered and their anti-hypersensitive effect was measured over time by the paw pressure test. Control rats received $100 \mu \mathrm{L}$ of vehicle (saline) solution intraplantarly and saline i.p..

\subsubsection{Abdominal contraction pain}

At predetermined time intervals (30 and 60) after drug 
administration, mice were injected intraperitoneally with a $0.6 \%$ $(\mathrm{w} / \mathrm{w})$ solution of acetic acid $\left(10 \mathrm{~mL} \mathrm{~kg}^{-1}\right)$, to induce pain sensation evident from typical abdominal contractions of animals named 'writhing'. The number of induced writhings was counted for $10 \mathrm{~min}$, starting $5 \mathrm{~min}$ after acetic acid injection [29].

\subsubsection{Monoiodoacetate-induced osteoarthritis}

Unilateral osteoarthritis was also induced by injection of monoiodoacetate (MIA, Sigma-Aldrich) into the rat tibio-tarsal joint [30]. On day 0 , rats were slightly anesthetized by $2 \%$ isoflurane, the left leg skin was sterilized with $75 \%$ ethyl alcohol and the lateral malleolus located by palpation; then, a 28-gauge needle was inserted vertically to penetrate the skin and turned distally for insertion into the articular cavity at the gap between the tibiofibular and tarsal bone until a distinct loss of resistance was felt. $2 \mathrm{mg}$ MIA in $25 \mu \mathrm{L}$ saline were delivered into the left articular cavity. The paw pressure was performed at day 14 . The tested compounds were p.o. administered. Control rats received $25 \mu \mathrm{L}$ of saline solution (day 0 ) in the tibiotarsal joint and saline i.p. at day 14 .

\subsubsection{Paw pressure test}

The pain threshold in the rat was determined with an analgesimeter (Ugo Basile, Varese, Italy) as described [31]. Briefly, a constantly increasing pressure was applied to a small area of the dorsal surface of the paw using a blunt conical probe. Pressure was increased until a vocalization or a withdrawal reflex occurred. The withdrawal threshold was expressed in grams, the test was repeated twice and the mean was considered as the value for each paw.

\subsubsection{Edema volume measurement}

Rat paw volumes were measured using a plethysmometer. Sixty min after the injection of carrageenan, the paw volume of the ipsilateral hind paw was measured and compared with carrageenan + vehicle-treated controls. The results are reported as paw volume expressed in $\mathrm{mL}$.

\subsubsection{Statistical analysis of behavioral measurements}

Results were expressed as means \pm s.e.m. and the analysis of variance was performed by one way ANOVA. A Bonferroni's significant difference procedure was used as post-hoc comparison. $\mathrm{P}$ values of less than 0.05 or 0.01 were considered significant. Data were analyzed by means of the "Origin 9" software (OriginLab, Northampton, USA).

\subsubsection{Cell culture and treatments}

HaCaT cells, (a cell line gift from Dr. F. Virgili), were grown in Dulbecco's modified Eagle's medium High Glucose (Lonza, Milan, Italy), supplemented with $10 \%$ FBS, $100 \mathrm{U} / \mathrm{ml}$ penicillin, $100 \mathrm{lg} / \mathrm{ml}$ streptomycin and $2 \mathrm{mM}$ L-glutamine as previously described [32]. Cell suspension containing 10 or 1105 viable cells/ml were used. Cells were incubated at $37 \mathrm{C}$ for $24 \mathrm{~h}$ in $95 \%$ air $/ 5 \% \mathrm{CO}_{2}$ until $80 \%$ confluency. HaCaT cells were treated with different doses of title compounds at different time points (30 min, 1, 3 and $24 \mathrm{~h}$ ). After treatment, cells or medium were collected for the several assays described below. Compounds were dissolved in DMSO at a concentration of $10 \mathrm{mM}$ as a stock solution. The stock was diluted to the required concentrations directly in the medium. The final concentration of DMSO in culture medium during compounds treatment did not exceed $0.1 \%(\mathrm{v} / \mathrm{v})$.

\subsection{Computational details}

All calculations performed in this work were carried out on Cooler Master Centurion 5 (Intel Core-i5 Quad CPU Q6600@
$2.40 \mathrm{GHz}$ ) with Ubuntu 10.04 LTS (long-term support) operating system running Maestro 9.2 and Maestro 9.3 (Schrödinger, LLC, New York, NY, 2011 and Maestro version 9.3, Schrödinger, LLC, New York, NY, 2012, respectively).

\subsubsection{Molecular docking studies}

4.2.1.1. Molecules preparation. Three-dimensional structures of compounds were built by means of Maestro (Maestro version 9.2, Schrödinger, LLC, New York, NY, 2011). Molecular energy minimizations were performed by means of MacroModel using the Optimized Potentials for Liquid Simulations-all atom (OPLS-AA) force field $2005[33,34]$. The solvent effects are simulated using the analytical Generalized-Born/Surface-Area (GB/SA) model [35], and no cutoff for nonbonded interactions was selected. Polak-Ribiere conjugate gradient (PRCG) method with 1000 maximum iterations and 0.001 gradient convergence threshold was employed. The compounds were treated by LigPrep application (LigPrep version 9.2, Schrödinger, LLC, New York, NY, 2011), implemented in Maestro suite 2011, generating the most probable ionization state of any possible enantiomers and tautomers at cellular $\mathrm{pH}$ value $(7 \pm 0.5)$.

4.2.1.2. Protein preparation. The three-dimensional structure of COX-2 was taken from PDB (PDB ID: 6COX) and imported into Schrödinger Maestro molecular modeling environment. The structure was submitted to protein preparation wizard implemented in Maestro suite 2011 (Protein Preparation Wizard workflow 2011) as previously reported [36,37]. This protocol through a series of computational steps, allowed us to obtain a reasonable starting structure of the proteins for molecular docking calculations by a series of computational steps. In particular, we performed diverse steps to (1) add missing residues or side-chains, (2) add hydrogens, (3) optimize the orientation of hydroxyl groups, Asn, and Gln, and the protonation state of His, and (4) perform a constrained refinement with the impref utility, setting the max RMSD of 0.30 . The impref utility consists of a cycles of energy minimization based on the impact molecular mechanics engine and on the OPLS_2005 force field [33,34].

4.2.1.3. Molecular docking. Docking studies were carried out by Glide (Grid-Based Ligand Docking with Energetics) using the ligands and the protein prepared as above-mentioned, applying Glide extra precision (XP) method [38,39]. Energy grid was prepared using default value of protein atom scaling factor (1.0 $\AA$ ) within a cubic box centered on the crystallized inhibitor. After grid generation, the ligands and the crystallized inhibitor were docked into the enzymes with default parameters (no constraints were added). The number of poses entered to post-docking minimization was set to 50. Glide XP score was evaluated. The XP method correctly accommodated the crystallized inhibitors into the binding site (data not shown).

4.2.1.4. Estimated free binding energy. The Prime/MM-GBSA method implemented in Prime software (Prime version 3.0, Schrödinger, LLC, New York, NY, 2011) consists in computing the change between the free and the complex state of both the ligand and the protein after energy minimization. The technique was used on the docking complexes of the selected compounds presented in this study. The software was employed to calculate the free-binding energy ( $\Delta \mathrm{G}_{\mathrm{bind}}$ ) as previously reported by some of us [40-42].

\section{Acknowledgements}

The authors are grateful to Dr Francesco Berrettini (CIADS, Siena University) for the X-ray data collection. 


\section{Appendix A. Supplementary data}

Supplementary data related to this article can be found at http:// dx.doi.org/10.1016/j.ejmech.2015.12.044.

\section{References}

[1] T. Grosser, S. Fries, G.A. FitzGerald, Biological basis for the cardiovascular consequences of COX-2 inhibition: therapeutic challenges and opportunities, J. Clin. Invest. 116 (2006) 4-15.

[2] M.N. Khan, Y.S. Lee, Cyclooxygenase inhibitors: scope of their use and development in cancer chemotherapy, Med. Res. Rev. 31 (2011) 161-201.

[3] S. Fiorucci, E. Distrutti, COXIBs, CINODs and H(2)S-releasing NSAIDs: current perspectives in the development of safer non steroidal anti-inflammatory drugs, Curr. Med. Chem. 18 (2011) 3494-3505.

[4] A. Zarghi, S. Arfaei, Selective COX-2 inhibitors: a review of their structureactivity relationships, Iran. J. Pharm. Res. 10 (2011) 655-683.

[5] T.N. Liebman, J.A. Stein, D. Polsky, Cyclo-oxygenase-2 inhibitors for chemoprevention of nonmelanoma skin cancer: is there a role for these agents? J. Am. Acad. Dermatol. 68 (2013) 173-176.

[6] J.L. Lee, H. Mukhtar, D.R. Bickers, L. Kopelovich, M. Athar, Cyclooxygenases in the skin: pharmacological and toxicological implications, Toxicol. Appl Pharmacol. 192 (2003) 294-306.

[7] C. Sticozzi, G. Belmonte, F. Cervellati, A. Di Capua, E. Maioli, A. Cappelli, A. Giordani, M. Biava, M. Anzini, G. Valacchi, Antiproliferative effect of two novel COX-2 inhibitors on human keratinocytes, Eur. J. Pharm. Sci. 49 (2013) $133-141$.

[8] W. Seebacher, J. Faist, A. Presser, R. Weis, R. Saf, T. Kaserer, V. Temml, D. Schuster, S. Ortmann, N. Otto, R. Bauer, Synthesis of new 4phenylpyrimidine-2(1H)-thiones and their potency to inhibit COX-1 and COX-2, Eur. J. Med. Chem. 101 (2015) 552-559.

[9] P. Singh, P. Prasher, P. Dhillon, R. Bhatti, Indole based peptidomimetics as antiinflammatory and anti-hyperalgesic agents: dual inhibition of 5-LOX and COX-2 enzymes, Eur. J. Med. Chem. 97 (2015) 104-123.

[10] T. Kaserer, V. Temml, Z. Kutil, T. Vanek, P. Landa, D. Schuster, Prospective performance evaluation of selected common virtual screening tools. Case study: cyclooxygenase (COX) 1 and 2, Eur. J. Med. Chem. 96 (2015) 445-457.

[11] A. Cappelli, M. Anzini, M. Biava, F. Makovec, A. Giordani, G. Caselli, L. Rovati, Substituted-1,5-Diaryl-2-Alkyl-pyrroles Highly Selective and Orally Effective COX-2 Inhibitors, in, WO2008014821, 2008.

[12] M. Anzini, M. Rovini, A. Cappelli, S. Vomero, F. Manetti, M. Botta, L. Sautebin, A. Rossi, C. Pergola, C. Ghelardini, M. Norcini, A. Giordani, F. Makovec, P. Anzellotti, P. Patrignani, M. Biava, Synthesis, biological evaluation, and enzyme docking simulations of 1,5-diarylpyrrole-3-alkoxyethyl ethers as selective cyclooxygenase- 2 inhibitors endowed with anti-inflammatory and antinociceptive activity, J. Med. Chem. 51 (2008) 4476-4481.

[13] M. Biava, G.C. Porretta, G. Poce, C. Battilocchio, F. Manetti, M. Botta, S. Forli, L. Sautebin, A. Rossi, C. Pergola, C. Ghelardini, N. Galeotti, F. Makovec, A. Giordani, P. Anzellotti, P. Patrignani, M. Anzini, Novel ester and acid derivatives of the 1,5-diarylpyrrole scaffold as anti-inflammatory and analgesic agents. Synthesis and in vitro and in vivo biological evaluation, J. Med. Chem. 53 (2010) 723-733.

[14] M. Biava, G.C. Porretta, A. Cappelli, S. Vomero, F. Manetti, M. Botta, L. Sautebin, A. Rossi, F. Makovec, M. Anzini, 1,5-Diarylpyrrole-3-acetic acids and esters as novel classes of potent and highly selective cyclooxygenase-2 inhibitors, J. Med. Chem. 48 (2005) 3428-3432.

[15] B.E. Smart, Fluorine substituent effects (on bioactivity), J. Fluor. Chem. 109 (2001) 3-11.

[16] H.J. Bohm, D. Banner, S. Bendels, M. Kansy, B. Kuhn, K. Muller, U. Obst-Sander, M. Stahl, Fluorine in medicinal chemistry, Chembiochem 5 (2004) 637-643.

[17] M. Anzini, C. Braile, S. Valenti, A. Cappelli, S. Vomero, L. Marinelli, V. Limongelli, E. Novellino, L. Betti, G. Giannaccini, A. Lucacchini, C. Ghelardini, M. Norcini, F. Makovec, G. Giorgi, R. Ian Fryer, Ethyl 8-fluoro-6-(3nitrophenyl)-4H-imidazo[1,5-a][1,4]benzodiazepine-3-carboxylate as novel, highly potent, and safe antianxiety agent, J. Med. Chem. 51 (2008) 4730-4743.

[18] M. Anzini, A. Di Capua, S. Valenti, S. Brogi, M. Rovini, G. Giuliani, A. Cappelli, S. Vomero, L. Chiasserini, A. Sega, G. Poce, G. Giorgi, V. Calderone, A. Martelli, L. Testai, L. Sautebin, A. Rossi, S. Pace, C. Ghelardini, L. Di Cesare Mannelli, V. Benetti, A. Giordani, P. Anzellotti, M. Dovizio, P. Patrignani, M. Biava, Novel analgesic/anti-inflammatory agents: 1,5-diarylpyrrole nitrooxyalkyl ethers and related compounds as cyclooxygenase- 2 inhibiting nitric oxide donors, J. Med. Chem. 56 (2013) 3191-3206.

[19] J.D. Pomonis, J.M. Boulet, S.L. Gottshall, S. Phillips, R. Sellers, T. Bunton, K. Walker, Development and pharmacological characterization of a rat model of osteoarthritis pain, Pain 114 (2005) 339-346.

[20] K. Kobayashi, R. Imaizumi, H. Sumichika, H. Tanaka, M. Goda, A. Fukunari, H. Komatsu, Sodium iodoacetate-induced experimental osteoarthritis and associated pain model in rats, J. Vet. Med. Sci. 65 (2003) 1195-1199.

[21] J. Fernihough, C. Gentry, M. Malcangio, A. Fox, J. Rediske, T. Pellas, B. Kidd, S. Bevan, J. Winter, Pain related behaviour in two models of osteoarthritis in the rat knee, Pain 112 (2004) 83-93.

[22] C. Guingamp, P. Gegout-Pottie, L. Philippe, B. Terlain, P. Netter, P. Gillet, Monoiodoacetate-induced experimental osteoarthritis: a dose-response study of loss of mobility, morphology, and biochemistry, Arthritis Rheum. 40 (1997) 1670-1679.

[23] M.J. Janusz, E.B. Hookfin, S.A. Heitmeyer, J.F. Woessner, A.J. Freemont, J.A. Hoyland, K.K. Brown, L.C. Hsieh, N.G. Almstead, B. De, M.G. Natchus S. Pikul, Y.O. Taiwo, Moderation of iodoacetate-induced experimental osteoarthritis in rats by matrix metalloproteinase inhibitors, Osteoarthr. Cartil. 9 (2001) 751-760.

[24] S.J. Wey, M.E. Augustyniak, E.D. Cochran, J.L. Ellis, X. Fang, D.S. Garvey, D.R. Janero, L.G. Letts, A.M. Martino, T.L. Melim, M.G. Murty, S.K. Richardson, J.D. Schroeder, W.M. Selig, A.M. Trocha, R.S. Wexler, D.V. Young, I.S. Zemtseva, B.M. Zifcak, Structure-based design, synthesis, and biological evaluation of indomethacin derivatives as cyclooxygenase-2 inhibiting nitric oxide donors, J. Med. Chem. 50 (2007) 6367-6382.

[25] T. Kawamori, C.V. Rao, K. Seibert, B.S. Reddy, Chemopreventive activity of celecoxib, a specific cyclooxygenase-2 inhibitor, against colon carcinogenesis, Cancer Res. 58 (1998) 409-412.

[26] B. Takkouche, C. Regueira-Mendez, M. Etminan, Breast cancer and use of nonsteroidal anti-inflammatory drugs: a meta-analysis, J. Natl. Cancer Inst. 100 (2008) 1439-1447.

[27] S. Hernandez-Diaz, L.A. Garcia Rodriguez, Nonsteroidal anti-inflammatory drugs and risk of lung cancer, Int. J. Cancer 120 (2007) 1565-1572.

[28] P. Srinath, P.N. Rao, E.E. Knaus, M.R. Suresh, Effect of cyclooxygenase-2 (COX2) inhibitors on prostate cancer cell proliferation, Anticancer Res. 23 (2003) 3923-3928.

[29] N. Mennini, S. Furlanetto, M. Bragagni, C. Ghelardini, L. Di Cesare Mannelli, P. Mura, Development of a chitosan-derivative micellar formulation to improve celecoxib solubility and bioavailability, Drug Dev. Ind. Pharm. 40 (2014) 1494-1502.

[30] L. Di Cesare Mannelli, D. Bani, A. Bencini, M.L. Brandi, L. Calosi, M. Cantore, A.M. Carossino, C. Ghelardini, B. Valtancoli, P. Failli, Therapeutic effects of the superoxide dismutase mimetic compound MnIIMe2DO2A on experimental articular pain in rats, Mediat. Inflamm. 2013 (2013) 905360.

[31] G.E. Leighton, R.E. Rodriguez, R.G. Hill, J. Hughes, kappa-Opioid agonists produce antinociception after i.v. and i.c.v. but not intrathecal administration in the rat, Br. J. Pharmacol. 93 (1988) 553-560.

[32] C. Sticozzi, G. Belmonte, A. Pecorelli, B. Arezzini, C. Gardi, E. Maioli, C. Miracco, M. Toscano, H.J. Forman, G. Valacchi, Cigarette smoke affects keratinocytes SRB1 expression and localization via $\mathrm{H} 2 \mathrm{O} 2$ production and HNE protein adducts formation, PLoS One 7 (2012) e33592.

[33] W.L. Jorgensen, D.S. Maxwell, J. TiradoRives, Development and testing of the OPLS all atom force field on conformational energetics and properties of organic liquids, J. Am. Chem. Soc. 118 (1996) 11225-11236.

[34] G.A. Kaminski, R.A. Friesner, J. Tirado-Rives, W.L. Jorgensen, Evaluation and reparametrization of the OPLS-AA force field for proteins via comparison with accurate quantum chemical calculations on peptides, J. Phys. Chem. B 105 (2001) 6474-6487.

[35] W.C. Still, A. Tempczyk, R.C. Hawley, T. Hendrickson, Semianalytical treatment of solvation for molecular mechanics and dynamics, J. Am. Chem. Soc. 112 (1990) 6127-6129.

[36] M. Brindisi, S. Brogi, N. Relitti, A. Vallone, S. Butini, S. Gemma, E. Novellino, G. Colotti, G. Angiulli, F. Di Chiaro, A. Fiorillo, A. Ilari, G. Campiani, Structurebased discovery of the first non-covalent inhibitors of Leishmania major tryparedoxin peroxidase by high throughput docking, Sci. Rep. 5 (2015) 9705

[37] A. Gasser, S. Brogi, K. Urayama, T. Nishi, H. Kurose, A. Tafi, N. Ribeiro L. Desaubry, C.G. Nebigil, Discovery and cardioprotective effects of the first non-Peptide agonists of the G protein-coupled prokineticin receptor-1, PLoS One 10 (2015) e0121027.

[38] T.A. Halgren, R.B. Murphy, R.A. Friesner, H.S. Beard, L.L. Frye, W.T. Pollard J.L. Banks, Glide: a new approach for rapid, accurate docking and scoring. 2 Enrichment factors in database screening, J. Med. Chem. 47 (2004) 1750-1759.

[39] R.A. Friesner, J.L. Banks, R.B. Murphy, T.A. Halgren, J.J. Klicic, D.T. Mainz M.P. Repasky, E.H. Knoll, M. Shelley, J.K. Perry, D.E. Shaw, P. Francis, P.S. Shenkin, Glide: a new approach for rapid, accurate docking and scoring. 1. Method and assessment of docking accuracy, J. Med. Chem. 47 (2004) 1739-1749.

[40] S. Brogi, S. Butini, S. Maramai, R. Colombo, L. Verga, C. Lanni, E. De Lorenzi, S. Lamponi, M. Andreassi, M. Bartolini, V. Andrisano, E. Novellino, G. Campiani, M. Brindisi, S. Gemma, Disease-modifying anti-Alzheimer's drugs: inhibitors of human cholinesterases interfering with beta-amyloid aggregation, CNS Neurosci. Ther. 20 (2014) 624-632.

[41] M. Brindisi, S. Gemma, S. Kunjir, L. Di Cerbo, S. Brogi, S. Parapini, S. D'Alessandro, D. Taramelli, A. Habluetzel, S. Tapanelli, S. Lamponi, E. Novellino, G. Campiani, S. Butini, Synthetic spirocyclic endoperoxides: new antimalarial scaffolds, Med. Chem. Commun. 6 (2015) 357-362.

[42] S. Giovani, M. Penzo, S. Brogi, M. Brindisi, S. Gemma, E. Novellino, M.J. Blackman, G. Campiani, S. Butini, Rational design of the first difluorostatone-based PfSUB1 inhibitors, Bioorg. Med. Chem. Lett. 24 (2014) $3582-3586$ 